\title{
STUDIES OF RHEUMATIC DISEASE. III. FAMILIAL ASSOCIATION AND AGGREGATION IN RHEUMATIC DISEASE
}

\author{
By ROSS L. GAULD AND FRANCES E. M. READ \\ (From the Cardiac Clinic of the Harriet Lane Home (Department of Pediatrics) of the Johns \\ Hopkins Hospital in cooperation with Child Hygiene Investigations of the United \\ States Public Health Service and the Department of Epidemiology, \\ Johns Hopkins University, School of Hygiene \\ and Public Health, Baltimore)
}

(Received for publication December 4, 1939)

At the present time the available evidence is insufficient to establish definitely the etiology of rheumatic disease although promising work has been done and is in progress. It has long been recognized that there is a tendency for the disease to occur more frequently in some families than in others. In a previous study (1) based upon the records of the families of patients admitted to the Cardiac Clinic of the Harriet Lane Home, careful statistical analysis suggested that hereditary constitution might be a factor in causing this aggregation. The evidence presented, however, did not exclude the possibility that the familial aggregation might be due solely or principally to common exposure either to a microbic cause and/or to any environmental factor, such as nutritional deficiency, which favored development of the disease.

If the disease were due solely to heredity, it would be expected that it would manifest itself in the various members of the family in such a way that its first acute manifestations (onsets) would be scattered along the time scale of family experience in a random fashion or affected solely by the age of its members. On the other hand, if in addition to hereditary predisposition, an environmental factor or factors were concerned, it would be expected that during certain periods of time in the family experience the risk of attack would vary according to the degree with which the environmental factor was acting. Thus we would expect a certain amount of grouping of the onsets of new cases occurring in the family, and after one member had developed acute manifestations of the disease there would be an increased incidence among his familial associates. This expectation would be justified regardless of the environmental factor involved, whether it be an infective agent and/or some other common environ- mental factor necessary for the development of the disease. In .other words, a tendency toward the grouping or aggregation of new cases within the family would appear at certain times, as in the case of infective disease such as diphtheria, scarlet fever, tuberculosis, and in nutritional deficiencies like pellagra.

To elucidate this relationship, the records of the group of families previously used in the study of the hereditary factors have been analyzed to determine the relationship of the first appearance of rheumatic manifestations ${ }^{1}$ (onsets) in the various members of these families along a time axis.

\section{MATERIAL AND METHODS}

The data upon which this report is based have been extracted from the medical records of 96 consecutive admissions of white children to the Cardiac Clinic of the Harriet Lane Home because they were suffering from rheumatic disease, and from the epidemiological record of this disease in their parents and siblings. A manifestation of rheumatic disease was defined as chorea, rheumatic fever, or rheumatic heart disease, and this definition is the same as that used in the two preceding articles $(1,2)$. Detailed information for each individual in $95^{2}$ of these families is available with respect to the date of birth, date of last observation, and the date of onset, duration, and type of each manifestation of rheumatic disease. The data relative to the rheumatic manifestations have, in most instances, been confirmed by hospital records. The relationship between the acute manifestations of rheumatic disease in the various members of each family, and the age of each individual when exposed to these attacks, can be ascertained from these reports. As an aid in this analysis, family graphs were drawn for each family showing the intrafamilial relationship of all attacks of rheumatic disease. A sample graph is shown in Figure 1.

1 This analysis deals only with the time relationship of primary onsets; second and subsequent attacks in any member have been considered as recurrences.

2 One family in which the records are incomplete has been excluded from the study. 


\section{HARRIET LANE HOME RHEUMATIC FEVER STUDY}

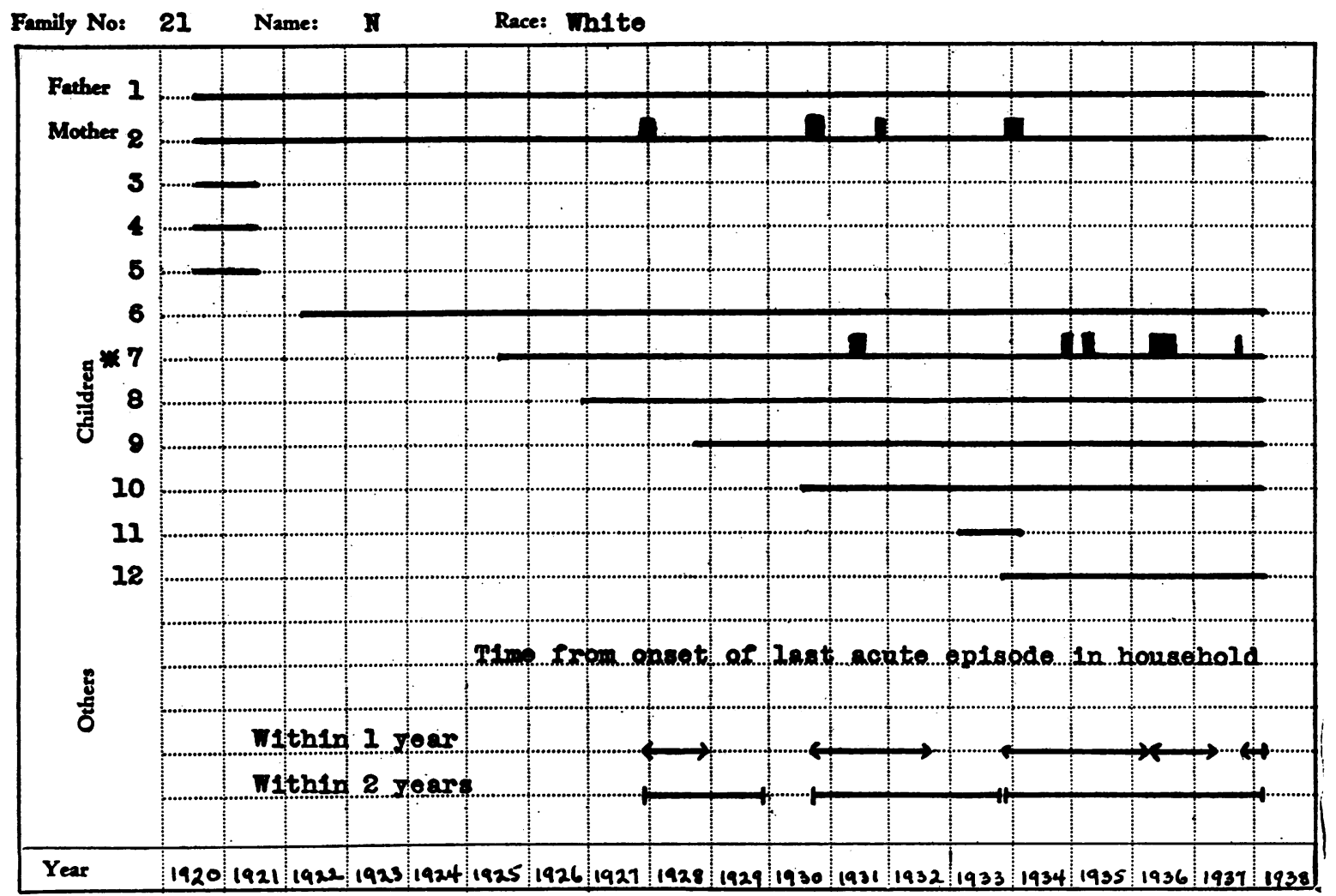

Fig. 1. Family Graph

Solid line indicates life-experience in the household. Acute episodes are indicated by solid blocks on top of line.

In order to hold the factor of heredity constant, as far as possible, the families were divided according to whether or not their parents had a history of rheumatic disease. There were 43 families in the group in which one or both parents were rheumatic, and 52 families in which neither parent had a rheumatic history. The children of these families have been studied to determine if an increased risk of developing the disease was associated with the occurrence of an acute episode of the disease in any other member of the household (adult or child).

It should be noted that the 95 families under study were selected because at least one member (a child) was admitted to the clinic suffering from rheumatic disease. The children who are responsible for the inclusion of their families in the study are known as "index cases" to distinguish them from their siblings who enter the study because of their familial relationship. The index case is not necessarily the first case to occur in the family, but it is the first to come to the clinic suffering from the disease. Because index cases are the means through which the families are selected and, by definition, must have had an attack of rheumatic disease, they have been excluded from the tabulations in order to avoid bias and attention has been confined to the occurrence of the dis- ease in their siblings who are unselected, except with regard to their familial relationship.

The final composition of the group studied was:

Rheumatic disease in parents . . . . .

No rheumatic disease in parents...... 52

191

The life-experience of these siblings, in each of the above groups, has been divided into that which preceded familial association ${ }^{8}$ with another member of the household (adult or child, including index cases) suffering from an acute manifestation (primary or recurrence) and that which followed such association. By this procedure it is possible to compare the incidence of new cases in the children during these two periods.

The occurrence of rheumatic disease in the children of these families could be expressed as the percentage who

8 The word association is preferred because the terms "exposure" or "contact" would imply that the effective environmental factor is opportunity for transmission of an infective agent. For present purposes it is desirable to avoid this assumption. 
had the onset of their first attack before, as compared to after, association with an acute episode, but such a statement is not fully satisfactory because it fails to take into consideration the time during which each was at risk during these periods and the possible differences in age susceptibility. For this reason, the experience of these children has been recorded in the terms commonly applied in the general population to express incidence of any disease, namely, the age-specific annual rates of morbidity.

In order to state the observations on this group in these terms it is necessary to reduce the prior and subsequent experience to a comparable base. This can be done by expressing the experience of these children in personyears of life before and after the date of the first intrafamilial association with an acute episode of the disease. By this method consideration can be given not only to the number of children in the family group, but also the length of time and the various ages during which each child was under observation.

If the purpose is to calculate morbidity prior to familial association with an acute attack, the age at which observation begins is at birth, because all of these children entered their respective families at birth. The age at which observation ends is dependent upon the occurrence of the first of four possible events: (1) death, (2) familial association with an acute attack in another member of the family, (3) onset of rheumatic disease, and (4) termination of observation without association. If the purpose is to show morbidity subsequent to association the observation begins with the age attained when first associated with an acute attack and ends with either (1) death, (2) onset of rheumatic disease, or (3) termination of observation. The actual procedure necessary to convert the observations into person-years of experience is that described by Frost (3) and Stewart, Gass, Gauld and Puffer (4) in their studies on tuberculosis.

\section{Incidence of rheumatic disease in the children of the families of rheumatic index cases, prior and subsequent to exposure to acute rheumatic manifestations in any member of the household}

The experience of the children in the study group expressed in person-years, along with the cases of rheumatic disease, and the annual morbidity rates are shown in Table I. In this table the children are grouped according to the history of rheumatic disease in their parents, and the experience divided into that which preceded and that which followed first association with an acute episode.

In calculating the total incidence of rheumatic disease for these two periods, only the experience of the children after their second birthday has been used. This has been done because the oc-
TABLE I

Life-experience, cases of rheumatic disease and annual attack rates among the siblings of 95 rheumatic index cases, prior and subsequent to first association with an acute manifestation of the disease, and according to the history of rheumatic disease in the parents

\begin{tabular}{l|l|l|c|c|c|c}
\hline \hline \multirow{3}{*}{ Age } & \multicolumn{2}{|c|}{$\begin{array}{c}\text { Prior to association } \\
\text { with an acute episode }\end{array}$} & $\begin{array}{c}\text { Subsequent to association } \\
\text { with an acute episode }\end{array}$ \\
\cline { 2 - 5 } & $\begin{array}{c}\text { Person- } \\
\text { years }\end{array}$ & Cases & $\begin{array}{c}\text { Rate } \\
\text { per } \\
100\end{array}$ & $\begin{array}{c}\text { Person- } \\
\text { years }\end{array}$ & Cases & $\begin{array}{c}\text { Rate } \\
\text { per } \\
100\end{array}$ \\
\hline
\end{tabular}

NO PARENTAL HISTORY OF RHEUMATIC DISEASE

\begin{tabular}{l|r|r|r|r|r|r}
\hline Under $2 \ldots \ldots \ldots$ & 338.5 & & & 20.50 & & \\
$2-4 \ldots \ldots \ldots \ldots$ & 425.5 & & & 62.50 & 2 & 3.20 \\
$5-14 \ldots \ldots \ldots \ldots$ & 706.5 & 10 & 1.41 & 336.00 & 9 & 2.68 \\
$15+\ldots \ldots \ldots \ldots$ & 89.5 & 2 & 2.23 & 121.75 & 2 & 1.64 \\
\hline $\begin{array}{c}\text { Total over } \\
\text { 2 years..... }\end{array}$ & 1221.5 & 12 & 0.98 & 520.25 & 13 & 2.50 \\
\hline
\end{tabular}

PARENTAL HISTORY OF RHEUMATIC DISEASE

\begin{tabular}{l|r|r|r|r|r|r}
\hline Under $2 \ldots \ldots$ & 243.0 & & & 48.50 & & \\
$2-4 \ldots \ldots \ldots$ & 257.0 & 4 & 1.55 & 128.25 & 3 & 2.34 \\
$5-14 \ldots \ldots \ldots$ & 305.0 & 6 & 1.96 & 397.50 & 18 & 4.53 \\
$15+\ldots \ldots \ldots \ldots$ & 17.0 & & & 99.00 & 4 & 4.04 \\
\hline $\begin{array}{c}\text { Total over } \\
\text { 2 years..... }\end{array}$ & 579.0 & 10 & 1.73 & 624.75 & 25 & 4.00 \\
\hline
\end{tabular}

currence of rheumatic manifestations under two years of age is rare, and no cases occurred during this age period in these families. ${ }^{4}$

When the annual rates for all ages over two years are compared, before and after association, it is found that the incidence in both groups of children is more than doubled in the period following association with an acute episode in the household. In those children whose parents gave no history of rheumatic disease, the rate increased from 0.98 to 2.50 per hundred per year, while in those whose parents had a history of rheumatic disease the increase was from 1.73 to 4.00 . Although based upon a comparatively small experience, these differences are sufficiently large to have statistical significance; the probability of a difference of this size occurring by chance in this group is only two in one hundred trials.

It should be further noted that, although the experience in each age group is not large enough to give statistical significance to the differences, with

4 The effect of this deduction from the total lifeexperience has been to minimize the differences found between the incidence in the two periods. 
one exception the age-specific rates are consistently higher after familial association with the acute disease.

From the data in Table $I$ it is also possible to compare the incidence in children of rheumatic and non-rheumatic parents. This comparison may be expressed in a ratio as follows :

Ratio of incidence $\frac{\text { Children of rheumatic parents }}{\text { Children of non-rheumatic parents }} \times 100$ Prior to association with an acute episode........ $\frac{176}{100}$ Subsequent to association with an acute episode..... $\frac{160}{100}$

It is interesting to note that the incidence is 60 to 80 per cent higher in the children of rheumatic parents than in the children of non-rheumatic parents, and that this ratio is not materially altered by association with an acute manifestation of the disease.

\section{The time relationship between association and the onset of new cases occurring subsequently}

The analysis up to this point has dealt with the total incidence of new cases of rheumatic disease among siblings of index cases which preceded and followed the first familial association with an acute episode. This fails to take into consideration the fact that a child might be associated with more than one acute episode in other members of the family before showing clinical evidence of having contracted it. If the occurrence of an acute episode in one member of the family is an indication that an environmental factor or factors, which have etiological significance, are operating at this particular time, then it would be expected that during the time interval closely following this event the risk of attack would be increased for other members in the same family. This in turn would be reflected in an increased case rate during a proximal subsequent period as compared with later periods.

In Table II is shown the distribution of 38 cases which occurred among the siblings of index cases according to interval elapsing between the time of association with the last prior acute episode and the time of onset.
TABLE II

Time interval between last prior association with an acute episode in another member of the family and the onset of rheumatic disease in 38 cases

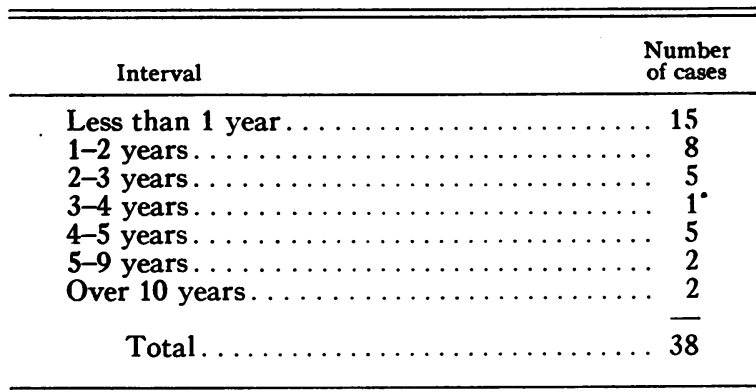

It will be noted that 15 of the 38 cases had their onset within one year, and $23(15+8)$ within two years of their last prior association with an acute episode in another member of the family. At first glance the distribution suggests that the risk is greatest among these children within a year or two following association with an acute attack. This tabulation, however, does not show the number of cases in proportion to the number of persons still under observation in the stated intervals and, accordingly, does not indicate the relative risk in these periods.

TABLE III

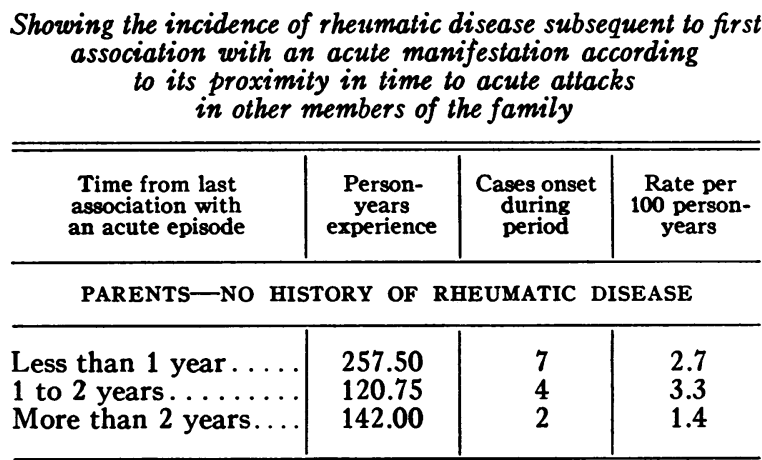

PARENTS-HISTORY OF RHEUMATIC DISEASE

\begin{tabular}{l|r|r|r}
\hline Less than 1 year..... & 312.25 & 8 & 2.5 \\
1 to 2 years........ & 130.50 & 4 & 3.1 \\
More than 2 years... & 182.00 & 13 & 7.1 \\
\hline
\end{tabular}

Using the onset of each separate acute episode as a focal point, it has been possible to divide the total experience of each child, subsequent to first association, according to its proximity to the onset of the last acute attack in another member of the family. This division was made in three time 
bands: (1) the experience which fell within one year following association with an acute episode, (2) that which was more than one year and less than two years following association, and (3) that which was more than two years following association. ${ }^{5}$

After the total experience following first association of each child was divided in this way, that of the group as a whole was obtained by adding the individual experiences together. Rates can be calculated for each interval by dividing the cases

In making this division, the procedure was to calculate for each individual the amount of experience following first association which was within one year and that which was within two years of association with an acute episode in the household. The detail for calculations on Individual 6, Family 21 (shown graphically in Figure 1), was:

\begin{tabular}{|c|c|c|c|c|c|c|}
\hline \multicolumn{2}{|c|}{$\begin{array}{l}\text { Beginning of } \\
\text { association }\end{array}$} & \multicolumn{2}{|c|}{ End of period } & \multicolumn{2}{|c|}{$\begin{array}{l}\text { Episodes with which } \\
\text { associated }\end{array}$} & \multirow{2}{*}{$\begin{array}{c}\text { Num- } \\
\text { ber } \\
\text { of } \\
\text { months } \\
\text { in } \\
\text { period }\end{array}$} \\
\hline Date & Age & Date & Age & $\begin{array}{l}\text { Date of } \\
\text { onset }\end{array}$ & $\begin{array}{c}\text { Indi- } \\
\text { vidual } \\
\text { at- } \\
\text { tacked }\end{array}$ & \\
\hline
\end{tabular}

A. EXPERTENCE WITHIN ONE TEAR OF BEGINNING OP ABSOCLATION WITH AN ACUTE EPIBODE

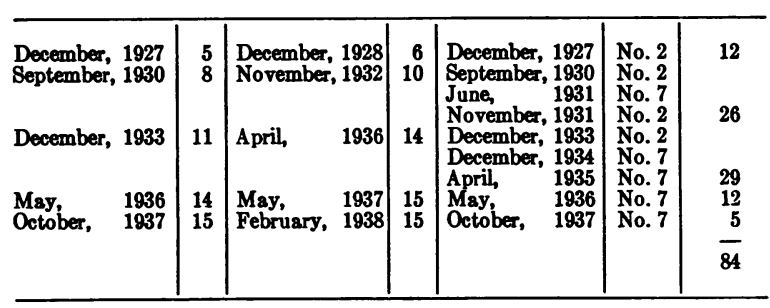

B. EXPERTENCE WTTHIN TWO TEARS OF BEGINNING OF ABSOCLATION WITH ÁN ACUTE EPIBODE

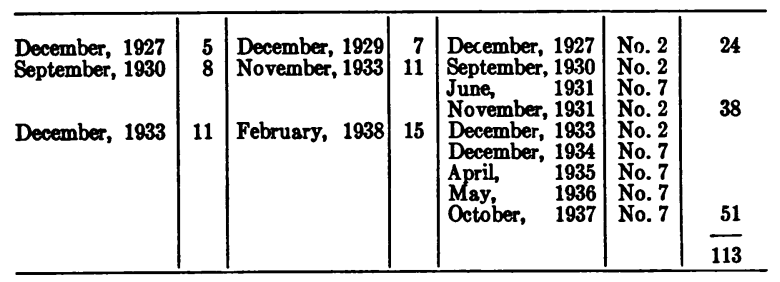

C. TOTAL EXPERIENCE BUBSEQUENT TO FIRST ABSOCLATION WITH AN ACUTE EPIBODE

\begin{tabular}{l|l|l|l|l|l|l}
\hline December, 1927 & 5 & February, 1938 & 15 & & $\begin{array}{c}\text { No.2 } \\
\text { and } \\
\text { No. 7 }\end{array}$ & 123 \\
\hline
\end{tabular}

Final allocation of experience:

Experience within one year of association (A) $\frac{84}{12}=7$ person-years

Experience more than one and less than two years following association (B-A) $\frac{113-84}{12}=2-5 / 12$ person-years

Experience more than two years following association (C-B) $\frac{123-113}{12}=\frac{10}{12}$ person-
years having their onset within it by the corresponding total person-years experience. These rates express the annual incidence of the disease in those at risk according to the proximity to all acute episodes with which the children were associated.

Although the experience is small, it shows no tendency for new cases appearing in other members of the family to be grouped or aggregated closely about the time at which one member comes down with acute manifestations. Indeed, if any inference at all is permissible, it is the contrary one, i.e., that after the disease has occurred in one member of the family it may be a matter of years rather than of months before another member is attacked.

\section{SUMMARY AND DISCUSSION}

The children of 95 families, in each of which one child entered the clinic because of some rheumatic manifestation, were studied with respect to the relationship of the occurrence of the disease among them to familial association with an acute episode of the disease in another member of the family. As far as possible hereditary factors were held constant throughout the analysis, and the index cases were excluded from the tabulations because of the bias which they introduced.

The analysis showed that the risk of contracting the disease among the siblings of the index cases was increased, following association with an acute episode in another member of the family, to more than twice that which prevailed prior to this association. This suggests that there is an environmental factor which plays a rôle in the causation of this disease.

The children of rheumatic parents had higher attack rates than the children of non-rheumatic parents, both before and after their first familial association with an acute episode. The interpretation of this finding should be made with caution because the children who have parents with a rheumatic history are, in most instances, also associated with what might be called the chronic quiescent phase of the disease in these parents. The higher incidence in these children could, therefore, be due either to an increased hereditary susceptibility or to long continued association with the disease in chronic form. Considered along with the findings of the previous article (1), the first would seem to be the more probable explana- 
tion, i.e., that heredity plays a definite rôle in the etiology of the disease.

The time relation between episodes in the family and the occurrence of subsequent cases in other members did not show a definite tendency for the incidence of subsequent attacks to be highest within short time intervals of an association with acute episodes. This finding would suggest that either long continued exposure to the cause (whether it be parasitic or non-parasitic) is necessary, or that the disease is slow in developing to the point where it becomes clinically manifest. In this respect, if it be due to an infection, it therefore resembles tuberculosis rather than an acute infection such as scarlet fever or diphtheria, and the results of exposure in any household should not be measured in weeks or months but in years.

These findings are consistent with the hypothesis that in the etiology of rheumatic disease there are both hereditary and environmental factors involved, and that the environmental factor to produce the disease must act over a long period of time, and/or the disease has a long period of subclinical development before becoming manifest. They are consistent with such an hypothesis, but do not prove it, because other explanations could fit the observed facts.

\section{CONCLUSIONS}

Careful observations over varying periods of time on 347 siblings of 95 children who were ad- mitted to the clinic because of some rheumatic manifestations showed that the attack rate

1. Increased after association with an acute episode.

2. Was higher among the children of rheumatic parents both before and after such association.

3. Showed no tendency, following association with an acute episode, to be higher within a short proximal period as compared with a more remote later period.

Acknowledgment is made by the authors to Dr. Kenneth Maxcy, Dr. Lowell J. Reed, and Miss Jean Downes for their assistance and advice in the preparation of this article.

\section{BIBLIOGRAPHY}

1. Gauld, R. L., Ciocco, A., Read, F., Further observations on the occurrence of rheumatic manifestations in families of rheumatic patients. J. Clin. Invest., 1939, 18, 213.

2. Read, F., Ciocco, A., and Taussig, H., The frequency of rheumatic manifestations among siblings, parents, uncles, aunts and grandparents of rheumatic and control patients. Am. J. Hyg., 1938, 27, 719.

3. Frost, W. H., Risk of persons in familial contact with pulmonary tuberculosis. Am. J. Pub. Health, 1933, 23, 426.

4. Stewart, H. C., Gass, R. S., Gauld, R. L., and Puffer, R., Tuberculosis studies in Tennessee: Infection, morbidity and mortality in the families of the tuberculous. Am. J. Hyg., 1937, 26, 527. 